\title{
Mediação e inclusão social: momentos no desenvolvimento do menino selvagem
}

\section{Mediation and social inclusion: moments in the development of the wild boy}

\author{
Jorge Gonçalves*, Maria Alexandra Peixoto** \\ *CIE- ISPA Instituto Universitário, Portugal **Escola Secundária Madeira Torres, Portugal
}

\begin{abstract}
Resumo
Pretende-se destacar a relação entre a mediação e inclusão social no desenvolvimento de uma criança selvagem, no estudo do caso retratado no filme "O menino selvagem", de François Truffaut. Foi realizada a caracterização inicial da criança enquanto Selvagem de Aveyron e as proposições do educador enquanto mediador. Foram analisados os métodos utilizados e os resultados obtidos. Foram identificados diferentes contextos de educação, assim como diferentes momentos no desenvolvimento da criança, com destaque para a criação de zonas de desenvolvimento proximal. Os resultados obtidos destacam as proposições atingidas e não atingidas por parte do mediador.

Palavras-chave: mediação, inclusão, criança selvagem
\end{abstract}

\begin{abstract}
It is intended to highlight the relationship between mediation and social inclusion in the development of a wild child, in the case of the study depicted in the film "The Wild Boy", by François Truffaut. The initial characterization of the child as wild Aveyron and the proposals of the educator as a mediator was held. The methods used and the results were analyzed. Educational contexts in different times in child development were identified, with emphasis on the creation of zones of proximal development. The results show the propositions achieved and not achieved by the mediator.
\end{abstract}

Keywords: mediation, social inclusion, wild child

\section{Introdução}

O caso do menino selvagem de Aveyron é retratado no filme de François Truffaut. Num dia de verão do ano de 1798, numa floresta francesa, foi encontrada por caçadores uma criança selvagem. Levada para Paris, foi observada pelo psiquiatra Pinel, que a considerou como um idiota irrecuperável e pelo jovem médico Itard que considerou ser possível recuperar o atraso provocado pelo seu isolamento total. Para provar a veracidade das suas razões, Itard pediu a tutela desta criança. Assim, com a ajuda da sua governanta, Sra. Guérin, iniciou a difícil tarefa de desenvolver as faculdades dos sentidos, intelectuais e afetivas de Victor.

Em entrevista, Truffaut confessou que esperou três anos para realizar "O Menino selvagem", após ter lido no Ie Monde, em 1966, a referência à tese de Lucien Malson sobre "As crianças selvagens". Truffaut considerou que o exemplo de isolamento mais nítido e mais instrutivo era o de Victor de Aveyron.

O professor Itard descreve o processo de aprendizagem através de um relatório ao Ministro do Interior da altura, assim como, na obra de 1801 "Da educação de um homem selvagem ou dos primeiros progressos físicos e morais do jovem selvagem de Aveyron”.

Vygotsky abordou a formação social da mente e o que designou como internalização das funções psicológicas superiores, "a reconstrução interna de uma operação externa" que "consiste numa série de transformações" (Vygotsky, 2003, p.74). Um processo interpessoal é transformado num processo intrapessoal, em que todas as funções aparecem primeiro no nível social (interpsicológico) e depois no nível individual (intrapsicológico).

Num contexto em que o termo função psicológica superior é utilizado como combinação entre o instrumento e o signo na atividade psicológica, a transformação de atividades que utilizem signos, de atividades de desenvolvimento de inteligência prática, da atenção voluntária e da memória é extremamente importante para o desenvolvimento dos processos mentais superiores. "A transformação de um processo interpessoal num processo intrapessoal é o resultado de uma longa série de eventos ocorridos ao longo do desenvolvimento" (Vygotsky, 2003, p.74). Na prática, assume-se um processo de transformação que se inicia no exterior do indivíduo e que posteriormente é assumido do ponto de vista pessoal.

Vygotsky salientou a importância da relação entre aprendizagem e desenvolvimento afirmando que "os problemas encontrados na análise psicológica do ensino não podem ser corretamente resolvidos ou mesmo formulados sem ter em conta a relação existente” (2003, p. 103). Neste sentido, este autor identifica três grandes posições capazes de agregar as principais conceções sobre esta relação: a aprendizagem é independente do desenvolvimento da criança, a aprendizagem e o desenvolvimento representam uma mesma unidade ou a aprendizagem e o desenvolvimento estão interligados e dependentes. 
Na primeira abordagem a aprendizagem é considerada como um processo puramente externo que não está envolvido ativamente no desenvolvimento. A relação entre a aprendizagem e o desenvolvimento poderia ser estabelecida numa base meramente utilitária, em que a aprendizagem se apoiaria nos avanços do desenvolvimento, não contribuindo para determinar a sua evolução. A segunda abordagem postula que aprendizagem é desenvolvimento. A relação de dependência não é assumida em contraponto à primeira abordagem, pois a aprendizagem e o desenvolvimento confundem-se e perdem identidade. A terceira posição de certa forma combina as duas anteriores e tenta superar os extremos definidos por cada uma.

Esta análise coloca a necessidade de se ter presente a importância da relação estabelecida entre aprendizagem e desenvolvimento e o papel relevante atribuído à zona de desenvolvimento proximal. Kozulin (2003) considera que apesar de este ser o conceito mais popular de Vygotsky, continua a ser pouco compreendido. Para tal, poderá ter contribuído o facto de ser usado em três contextos diferentes. No contexto do desenvolvimento, a zona de desenvolvimento proximal é usada para explicar as funções psicológicas emergentes na criança. No contexto da aplicação, explica a diferença entre os rendimentos individuais e ajudados da criança, ambas em situações de avaliação e na aprendizagem. Finalmente, a zona de desenvolvimento proximal é usada como um "espaço" metafórico onde conceitos espontâneos da criança se encontram com conceitos "científicos" fornecidos por professores ou outros mediadores da aprendizagem.

\section{Método}

\section{Participantes}

Foi realizada a análise e observação do estudo de caso da criança selvagem de Aveyron, retratado no filme de François Truffaut “O menino selvagem”.

\section{Materiais}

\section{“L’enfant sauvage”, de François Truffaut}

Filme interpretado pelo próprio François Truffaut (Dr. Jean Ttard), Jean-Pierre Cargol (Victor del'Aveyron), Françoise Seigner (Sra. Guérin), entre outros. Produzido por Marcel Berbert e Claude Miller para "Les Films du Carrosse e Lês Artistes Associes. Argumento e diálogos de François Truffaut e Jean Gruault, com base em "Mémorie et Rapport sur Victor d'Aveyron de Jean Itard (1806)". Gravado em julho/agosto de 1969. Cópia da Cinemateca Francesa, em 35 mm, preto e branco, versão original sem legendas, com a duração de 86 minutos.

\section{Relatório do Professor Itard}

Relatório apresentado ao Ministro do Interior sobre os desenvolvimentos de Victor de Aveyron, versão portuguesa traduzida por Gonçalves e Peixoto (2001). Quando o Professor Itard defende que é possível reduz a cinco proposições principais os seus objetivos relativamente à educação do selvagem de Aveyron.:

- Primeira proposição - “Atraí-lo para a vida social, tornando-lha mais suave do que a que levou até então e, sobretudo, mais parecida com a vida que acabava de deixar";

- Segunda proposição - "Despertar a sensibilidade nervosa com os estimulantes mais energéticos e às vezes pelas emoções mais vivas da alma” ;

- Terceira proposição - "Alargar-lhe a esfera das suas ideias, criando-lhe necessidades novas e multiplicando as suas relações com os seres que o rodeiam;

- Quarta proposição - "Levá-lo ao emprego da palavra, determinando o exercício da imitação pela lei imperiosa da necessidade";

- Quinta proposição - "Exercitar, durante algum tempo, sobre os objetos das suas necessidades físicas, as mais simples operações do espírito, determinando de imediato a aplicação sobre objetos de instrução”.

Da educação de um homem selvagem ou dos primeiros progressos físicos e morais do jovem selvagem de Aveyron

Escrito por Jean-Marc Gaspard Itard, versão traduzida por Gonçalves e Peixoto (2001).

\section{Procedimento}

Foram analisados os diferentes momentos do filme que permitem estabelecer a relação com as proposições do mediador (Dr. Itard) da criança selvagem.

\section{$1^{\circ}$ Momento: Na Selva}

Uma camponesa anda a colher bagas na floresta. Ouve um barulho de arbustos a mexer. Olha e, ao ver um animal estranho, larga o cesto e foge. Esse animal estranho era um ser humano. Um menino que andava com os pés e as mãos, trepava às árvores, comia bolotas e raízes, coçava a cabeça e o corpo como os animais, tinha um olhar vago.

\section{$2^{\circ}$ Momento: A Caçada}

A camponesa vai chamar três caçadores que vieram com cães e espingardas tentar caçar esse "ser" selvagem. Sentindo-se perseguido, o menino começa a fugir e sobe a uma árvore. Mas, ao pendurar-se num ramo, cai e, nesse momento, um dos cães apanha-o e morde-o. Embora com menos força e biologicamente mais mal preparado, a sua inteligência é maior o que lhe permite resolver a situação em seu favor: aperta o pescoço do cão até o matar. A caçada prossegue. Quando os caçadores estão prestes a apanhar o menino, ele foge novamente, escondendo-se num buraco no chão. $\mathrm{O}$ caçador acende então uma tocha com fumo que mete dentro do buraco. $\mathrm{O}$ menino é obrigado a sair. Tenta ainda fugir mas os caçadores conseguem apanhá-lo. Tapam-no e levam-no com eles para uma Quinta.

$3^{\circ}$ Momento: Conhecimento público da descoberta da criança selvagem

O menino selvagem é entregue aos cuidados de um aldeão que o protege da curiosidade dos camponeses. Entretanto, em Paris, um médico lê uma notícia sobre este acontecimento e reconhece como seria útil examinar esta criança e determinar o seu grau de inteligência. Itard compreende que se trata de uma situação excecional: um adolescente privado de educação por ter vivido afastado dos indivíduos da sua espécie. 


\section{$4^{\circ}$ Momento: Ida para a prisão de Rodez}

Acorrentado num palheiro, o menino tenta fugir diversas vezes. Para evitar tal facto é transferido para a prisão de Rodez. Cuvier e Sicard conseguem uma autorização do Ministério do Interior para transferirem o selvagem para Paris. Na prisão, um guarda tenta dar-lhe banho. O selvagem revolta-se e morde-o. Só a presença e a ternura do aldeão que o havia recebido, permitem acalmá-lo.

\section{$5^{\circ}$ Momento: Ida para Paris}

O selvagem de Aveyron é levado para Paris numa carruagem, preso por uma trela. Ao atravessar um rio, os passageiros são obrigados a sair da carruagem. Nesse momento o selvagem consegue fugir para a margem do rio. Afinal o seu objetivo era apenas beber água. Já em Paris, uma conversa entre Itard e Pinel a propósito de uma notícia do jornal na qual se afirmava que o selvagem iria, aos poucos, tomar os hábitos dos homens civilizados e se deixaria maravilhar com as belezas da capital. Todos esperavam que uma educação rápida permitisse recolher informações sobre a vida passada do selvagem.

\section{$6^{\circ}$ Momento: Exames realizados ao Menino} Selvagem

O selvagem é levado ao professor Itard e ao professor Pinel que o observaram de imediato: media 1,39 m de altura, tinha pele fina, cor escura, rosto oval, olhos negros, grandes pestanas, boca média, língua normal e bem distinta, dentição normal. Os observadores calcularam que deveria ter entre 11 a 12 anos. Sentado de costas para a porta do consultório não reage ao barulho da porta que se fecha. No entanto, o aldeão que dele se ocupou na aldeia afirmou tê-lo visto voltar-se quando se partia uma noz nas suas costas. Os sentidos da criança estavam invertidos: o olfato mais desenvolvido, seguido do gosto, visão e por fim o tato. Tinha cicatrizes, arranhões e rasgões pelo corpo, a maior parte devidas a mordeduras de animais. Tinha uma cicatriz diferente das outras no pescoço, uma sutura de $40 \mathrm{~mm}$, que parecia ser um corte provocado por um instrumento afiado. Nessa altura, deveria ter três a quatro anos de idade porque, se fosse mais novo, não teria sobrevivido pelos seus próprios meios. Como afirma o professor Itard: "O ferimento não pode ser a causa do mutismo e ele não fala". A "única causa é o isolamento em que viveu até aqui".

\section{$7^{\circ}$ Momento: No colégio dos surdos-mudos}

No colégio de surdos-mudos, durante os recreios, foge das outras crianças e esconde-se debaixo de montes de folhas. Quando o pretendem deitar, refugia-se debaixo da cama, onde dorme. Se chove, em vez de se abrigar como qualquer outra criança, fica alegre, corre e salta ao som da chuva. Maltratado pelas outras crianças, explorado pelos guardas (os parisienses fazem excursões ao colégio para verem o "menino selvagem"), o menino selvagem tornava estridente a sua diferença radical. Por um lado, o professor Pinel considera o selvagem como um idiota, em tudo semelhante aos que tratava em Bicêtre. Sugere, por isso, que seja levado para aquela instituição de deficientes mentais. Segundo Pinel, o selvagem tinha sido abandonado e esfaqueado pelos pais por ser anormal. Pelo contrário, para o professor Itard, ele não é idiota. Propõe-se tentar educá-lo e, nesse sentido, pede à Administração que lho confie. Concedida essa autorização, leva-o para sua casa, perto da aldeia de Batignolles, onde a sua governanta, Sra. Guérin, cuida dele.

$8^{\circ}$ Momento: Chegada a casa do Prof. Itard e habituação à vida civilizada

A governanta recebe a criança com efusiva manifestação de ternura. O professor verifica que a criança é insensível ao fumo do tabaco, a todas as manifestações afetivas e suportava muito bem o calor, pois apanhou brasas com as mãos. Decide dar-lhe banho em água a escaldar e simultaneamente salpica-o com água fria, para lhe estimular a sensibilidade cutânea. Será necessário ensinar-lhe tudo, inclusivamente ensinar-lhe a escutar e a ver. O professor obriga-o a uma postura direita e ensina-o a andar sem dobrar os joelhos. À refeição, quando a Sra. Guérin lhe põe um prato de sopa à frente, o menino imediatamente debruça a cara sobre o prato como um animal. Então, a governanta ensina-o a comer com a colher. Quando o professor lhe pretende calçar os sapatos pela primeira vez, o menino reage fortemente e não consegue andar. Aos poucos tornou-se sensível à temperatura. Acende velas com fósforos, e começa a apreciar as roupas, que até então recusava. Espirra pela primeira vez. Após o regresso a casa, o menino põe a mesa com os respetivos talheres, tal como a Sra. Guérin lhe tinha ensinado. Vai à cozinha buscar uma taça e começa a bater no avental da Sra. Guérin. Encorajado com estes progressos das capacidades comunicativas do menino, o professor começa a fazer alguns jogos. Aos poucos, o professor tenta reduzir-lhe os passeios, as refeições e o tempo de cama. O seu objetivo é tornar os seus dias mais proveitosos. Num certo dia, o professor e a Sra. Guérin, apercebem-se que a criança se volta para trás ao ouvir o som "o", razão pela qual começam a chamar-lhe Victor. Ao perceber o gosto especial que Victor tem pelo leite, o professor tenta que ele diga a palavra leite. Victor só diz a palavra leite após o professor lhe dar a tigela com o leite. Se a palavra saísse antes da concessão da coisa desejada, ele teria aprendido a função da palavra. A palavra para Victor é apenas expressão insignificante e inútil do prazer sentido, considera o professor Itard.

\section{$9^{\circ}$ Momento: Passados três meses}

O professor coloca-o de frente para um espelho com uma vela acesa à sua frente e tenta que este o imite a fazer determinados sons. Com um tambor no colo e de olhos vendados, imita o som produzido pelo professor no tambor. A certa altura, quando a Sra. Guérin arruma a casa, troca acidentalmente o lugar de certos objetos. Victor volta a colocá-los no sítio correto. O professor Itard resolve então aproveitar esta sua "paixão pela arrumação". O professor Itard começa por desenhar vários objetos no quadro, pedindo a Victor que pendurasse os próprios objetos no quadro, por cima de cada desenho. O menino consegue colocar os objetos no sítio. O professor recompensa-o com um copo de água. A etapa seguinte consiste em apagar o desenho dos objetos deixando apenas o seu nome. Victor olha e tem um ataque de raiva, esperneando no chão. O professor 
reconhece que a distância entre passar da representação de um objeto para a sua representação alfabética é um salto enorme. Vai procurar um método progressivo em que cada dificuldade vencida o eleve ao nível de dificuldade a vencer. Nesse sentido, manda fazer um alfabeto de madeira. Victor aprende depressa a classificar as letras. No entanto, o prof. Itard apercebeu-se que o fazia amontoando as letras pela ordem inversa da sua classificação alfabética. O menino tinha conseguido inventar um expediente de memória que o dispensava da comparação e da apreciação. A etapa seguinte consiste em misturar as letras e pedir a Victor para as colocar no devido lugar. Novo ataque de raiva.

\section{$10^{\circ}$ Momento: Passados sete meses}

Reiniciando os exercícios, o professor tenta novamente que Victor coloque as letras do alfabeto de madeira, mas este tem outro ataque de cólera. O professor recorre ao quarto escuro. Quando o tira do quarto escuro, Victor chora pela primeira vez. Após esta crise, o menino começa a colocar as letras do alfabeto de madeira no lugar certo. Quando Victor pede para lhe darem leite, o professor deu-lhe as letras de madeira para ele formar a palavra leite. Após umas tentativas, o menino consegue fazê-lo corretamente. Quando volta a casa do Sr. Lémeri, Victor leva consigo as letras de madeira e coloca-as em cima da mesa, como forma de pedir leite à Sra. Lémeri. O professor também tenta ensinar as vogais, sem sucesso. O professor Itard tenta então ensinar Victor a escrever no quadro com giz. À medida que o professor escreve, o menino imita-o. Entretanto, o professor consegue que Victor aprenda a relação dos objetos com a sua representação alfabética. Quando lhe pede para ir buscar certos objetos, apontando para a palavra e pronunciando-a, ele traz esses mesmos objetos. Há vários dias que Victor está privado das suas saídas diárias, porque o professor está doente com reumatismo. A Sra. Guérin manda Victor buscar água. Ao ver a janela aberta, Victor corre para a floresta onde dorme nessa noite. Contudo, já não consegue sobreviver na floresta. $\mathrm{Na}$ manhã do dia seguinte é visto numa quinta, quando tentava roubar uma galinha, mas foge ao ser descoberto. Ao regressar a casa, Victor fez passar as mãos de Sra. Guérin no seu rosto. Ao assistir a esta cena o professor faz-lhe uma festa na cabeça: "já não és selvagem, embora não sejas ainda um homem”.

\section{Resultados}

Quando o Professor Itard defende que é possível a sua educação, reduz a cinco proposições principais os seus objetivos relativamente à educação do selvagem de Aveyron.

Primeira proposição - “Atraí-lo para a vida social, tornando-lha mais suave do que a que levou até então e, sobretudo, mais parecida com a vida que acabava de deixar"

Tendo constatado que a criança conhecia apenas quatro coisas: dormir, comer, não fazer nada e correr pelos campos e não querendo quebrar totalmente as rotinas da sua vida passada, Itard tinha como objetivos, e alcançou-os, tornar as corridas do selvagem mais raras, a sua alimentação menos “copiosa” e menos frequente, a sua estadia na cama menos prolongada e, também consequentemente os dias da semana melhor aproveitados para a sua instrução. O Prof. Itard propõe-se sem uma intenção de sociabilização agressiva, aproximar os tempos da criança e seu aproveitamento dos tempos de um ser humano socializado.

Segunda proposição - "Despertar a sensibilidade nervosa com os estimulantes mais energéticos e às vezes pelas emoções mais vivas da alma”

Partindo de uma realidade que testemunhava uma inação da generalidade dos sentidos da criança e tendo, por base, a ideia de que “ a sensibilidade está em razão direta com a civilização”, o professor Itard tentou aquilo que denominou como uma excitação geral dos órgãos. Após apenas três meses, o tato mostrava-se sensível à impressão dos corpos quentes e frios, lisos e rugosos, moles ou duros. O olfato demonstrava uma reação (espirrava) à menor irritação. O próprio paladar estava mais refinado, o que se refletia na escolha e tratamento que dava aos alimentos. Se o objetivo inicial de uma excitação geral dos órgãos não foi totalmente alcançado deve-se ao facto de o ouvido e a vista não terem reagido da mesma forma, realçando, segundo Itard, a sua complexidade e a necessidade de tratamento particular e aprofundado.

\section{Terceira proposição - "Alargar-lhe a esfera das suas ideias, criando-lhe necessidades novas e multiplicando as suas relações com os seres que o rodeiam}

O professor Itard tenta atingir este objetivo, principalmente, através de uma série de situações, que passam por divertimentos relacionados com as necessidades digestivas. Apesar disso, Itard assume que não conseguiu criar no menino selvagem gostos que seriam próprios para a sua idade. O professor ressalta também a influência poderosa que os jogos de infância têm os primeiros desenvolvimentos do pensamento.

Quarta proposição - “Levá-lo ao emprego da palavra, determinando o exercício da imitação pela lei imperiosa da necessidade”

O Professor Itard afirmou que se quisesse mostrar só aspetos positivos não entraria com esta quarta proposição. Baseado na premissa de que para falar são precisas duas operações distintas, a perceção do som da voz e a apreciação da articulação desse som, Itard considera que a palavra é uma espécie de música à qual alguns ouvidos, embora bem constituídos podem ser insensíveis. Assim, a dificuldade em empregar a palavra no selvagem estaria diretamente ligada ao facto de não possuir uma série de capacidades próprias de uma criança mais nova que facilitam o uso da voz e da linguagem. Itard, considera ainda que o uso da palavra é ainda mais inibido pela facilidade com o selvagem exprime as suas necessidades doutra maneira, que não pelo uso da palavra.

Quinta proposição - “Exercitar, durante algum tempo, sobre os objetos das suas necessidades físicas, 
as mais simples operaç̃̃es do espírito, determinando de imediato a aplicação sobre objetos de instrução"

Nesta proposição os objetivos propostos passam por uma exercitação contínua da atenção, memória, juízo e todas as faculdades dos seus sentidos. Para atingir o proposto, Itard utiliza características que o menino já trazia consigo. Por um lado, através da procura da satisfação das suas necessidades, era possível fomentar o desenvolvimento da memória e da sua inteligência. Por outro, o Professor utilizou o gosto do menino pela ordem para exercitar a atenção sobre as coisas.

\section{Discussão}

A necessidade de compreensão da diferença entre o que a criança faz, efetivamente, e o que será capaz de fazer, coloca o professor num papel relevante e mobilizador das suas capacidades, propiciando o seu desenvolvimento mental. As situações de educação vividas pelo menino selvagem podem ser categorizadas da seguinte forma: Educação da sensibilidade, relacionada com os sentidos, Educação dos sentimentos, relacionada com a variedade de sentimentos desenvolvidos para com as diferentes pessoas, Educação da sociabilidade, relacionada com os hábitos quotidianos, e Educação moral, relacionada com o sentido de justiça, do bem e do mal.

\section{Educação da sensibilidade}

Victor desenvolveu a capacidade de escutar distintamente algumas palavras de sílabas e conseguiu distinguir com precisão diferentes entoações da linguagem, quer exprimissem censura, cólera, tristeza ou amizade. Itard passa então ao desenvolvimento da visão, fazendo-o comparar, distinguir letras de metal e colocá-las na ordem para formar algumas palavras. Através da audição e da visão, Victor desenvolveu a capacidade de ler algumas palavras. Exercitado este sentido, Itard desenvolveu o tato, com o intuito de levar Victor a distinguir a configuração dos objetos pela sua forma. O sentido do olfato foi retirado dos objetivos do professor Itard, por considerar que este sentido está relacionado apenas com funções digestivas, e para além disso, já o havia excitado numa situação inicial. Pelo contrário, Itard considerou importante o exercitar do sentido do paladar, pois considerava que este sentido ultrapassava as funções limitadas que lhe são atribuídas pela natureza, dado que a civilização o converteu em órgão de prazeres variados.

\section{Educação dos sentimentos}

Como resultado da convivência diária com o professor Itard e com a Sra. Guérin desenvolveu diferentes sentimentos, que eram inicialmente apenas despertados pelas suas necessidades, mais tarde deram origem a sentimentos menos interessados, demonstrando gratidão e amizade por aqueles que o rodeavam. Ao longo do desenvolvimento do menino selvagem, Itard assiste à demonstração de sentimentos de euforia e alegria quando Victor consegue superar as dificuldades dos exercícios que o professor lhe propõe, mas também a sentimentos de frustração, fracasso e impotência quando não consegue alcançar o pretendido. O professor Itard realça que apesar de mostrar alguns sentimentos de homem civilizado, não deixa de se mostrar sensível aos sentimentos relacionados com a sua vida primitiva.

\section{Educação da sociabilidade}

Ao longo de toda a descrição da evolução do menino selvagem são vários os gestos e os hábitos quotidianos que o professor lhe transmite com o intuito de 0 sociabilizar. O professor mostrou ao menino selvagem como andar de forma ereta, como caminhar ao seu lado quando passeavam, a Sra. Guérin ensinou-o como comer de faca e garfo, como se vestir, como cumprimentar as pessoas. Incutiram no menino selvagem hábitos de higiene, de alimentação, de sentido do horário.

\section{Educação moral}

No início, Itard reparou que, por várias vezes, o jovem Victor quando sentia fome tirava comida sem que lhe dessem autorização. Mas tirava-a de uma forma bastante natural e por isso não se podia dizer que este a roubava. No entanto, como Itard pretendia incutir-lhe hábitos e normas decidiu reprimir esta tendência. Para acabar de vez com estes atos, Itard arrancava-lhe das mãos a comida roubada e comia à sua frente. Com estes gestos, Itard conseguiu acabar com os pequenos delitos do jovem Victor. Mas para se certificar da interiorização do sentido da justiça, o professor Itard decidiu castigar injustamente Victor, tentando-o fechar num quarto escuro depois deste ter sido bem sucedido nos seus exercícios. Victor, sentindo-se injustiçado, resistiu de uma forma violenta e mordeu o professor. Sendo assim, esta reação de Victor representava um ato inegável de que o sentimento de justo e injusto estava presente nele. O professor Itard considerou então, que ao provocar o desenvolvimento deste sentido, elevava o menino selvagem ao nível do homem moral.

Assim, por último, salienta-se a ideia de Gondra de que a infância não pode ser pensada no exterior das instituições que lhe são associadas, como a casa e a escola (2010), em particular quando se pretende estabelecer a relação entre os processos de aprendizagem e desenvolvimento num contexto de mediação tão incomum (Pereira, 2012).

\section{Referências}

Gonçalves, J.; Peixoto, M. A. (2001). Estudo do caso de uma criança selvagem retratado no filme "O menino selvagem” de François Truffaut. Lisboa: Universidade de Lisboa. Disponível em http://www.educ.fc.ul.pt/docentes/opombo/cinema/do ssier/meninoselvagem.pdf

Gondra, J. G. (2010). The emergence of childhood. Educação em Revista, 26(1), 195-214. http://dx.doi.org/10.1590/S0102-46982010000100010

Kozulin, A. (2003). Vygotsky's educational theory in cultural context. Cambridge University Press.

Pereira, T. M., \& Galuch, M. T. B. (2012). O garoto selvagem: a importância das relações sociais e da educação no processo de desenvolvimento humano. Perspectiva, 30(2), 553-571. http://dx.doi.org/10.5007/2175-795X.2012v30n2p553

Vygotsky, L. S. (2003). A formação social da mente: o desenvolvimento dos processos psicológicos superiores. Martins Fontes. 